\title{
The Effect of Schematic Knowledge on Iranian EFL Learner's Reading Comprehension
}

\author{
Omid Ostad \\ University of Guilan, Rasht, Guilan, Iran \\ E-mail: omidostad007@gmail.com \\ Mohammad Tarang (Corresponding author) \\ University of Guilan, Rasht, Guilan, Iran \\ E-mail: mohammadtarang@yahoo.com
}

\author{
Received: 04-05- 2015 \\ Accepted: 15-07- 2015 \\ Advance Access Published: August 2015 \\ Published: 01-11- 2015 \\ doi:10.7575/aiac.ijalel.v.4n.6p.154 \\ URL: http://dx.doi.org/10.7575/aiac.ijalel.v.4n.6p.154
}

\begin{abstract}
A large number of variables influence the way a learner comprehends a reading passage, one of which is prior knowledge. This study examines this variable to discover its effect on the reading comprehension ability of Iranian EFL learners. The data was elicited from sixty-eight intermediate level students who were studying English as a foreign language in a private language institute in Rasht, a city in the north of Iran. After an English Proficiency test, they were divided in two groups, an experimental group and a control one. A pre-test was administered to both groups. Consequently, the experimental group received the treatment. Finally, a post-test was administered to both groups in order to find out the differences between two groups. The experimental group outperformed the control group. It was concluded that schematic knowledge has a noticeable significance on improving the reading comprehension skill of Iranian EFL Learners. Therefore, the activation of schematic knowledge prior to the reading process can be a useful method in teaching reading comprehension in language classes.
\end{abstract}

Keywords: schematic knowledge, EFL learners, reading comprehension

\section{Introduction}

According to Chall (1983), Students constantly confront new information, particularly once they progress to the upper elementary grades and are in transition from 'learning to read' to 'reading to learn'. Integrating new material into existing knowledge base, constructing new understanding, and adapting existing conceptions and beliefs as needed are necessary elements in reading effectively. Also, proficiency at these tasks is essential to literacy (Davis \& Winek, 1989).

Several studies have suggested that text comprehension is dependent upon prior knowledge. Voss and colleagues provided evidence that domain-specific knowledge influences understanding (Chiesi, Spilich, \& Voss, 1979; Means \& Voss, 1985; Voss, Vesonder, \& Spilich, 1980). They found that 'high-knowledge' readers recalled more information than 'low-knowledge' readers and concluded that the former employed their knowledge during reading to construct an organised representation of the text.

Perhaps the most well known effect of background knowledge is its ability to directly influence the understanding of what the reader reads (Stahl, Hare, Sinatra, \& Gregory, 1991). It makes perfect sense - the more you know about a topic, the more likely it will be for you to comprehend what it is written about. Alfassi (2004) believes that when a reader's background knowledge is more extensive, s/he will acquire the new information given by the text more easily. Along with this idea, Tarchi (2009) stated that the ability to infer meaning from texts written about social studies is positively influenced by the level of background knowledge each learner has.

\subsection{Definition of Key Terms}

Schematic knowledge: The specialised words 'schematic knowledge', 'prior knowledge', or 'background knowledge' can be used interchangeably. Stevens (1980) defines background knowledge quite simply as '...what one already knows about a subject' (p.151). Prior knowledge is 'all knowledge learners have when entering a learning environment that is potentially relevant for acquiring new knowledge' (Bieman's \& Simon's1996. p.6). Dochy et al., (1995) provide a more elaborate definition, describing prior knowledge as all knowledge one has, including explicit and implicit knowledge, meta-cognitive knowledge, and conceptual knowledge. This definition is quite similar to Schallert's (1982) definition. Thus, while scholars' definitions of these two terms are often worded differently, they typically describe the same basic concept. 
Reading is one of the four skills in EFL/ESL situations. Reading occupies the most class time for a variety of purposes. Without having reading proficiency, second language learners cannot perform well in communication. Consequently, experts have attempted to devise new plans and approaches to meet such educational needs. According to Celce-Murcia (2001), reading is gradually being recognised as a valuable source of language input, particularly for students in a learning environment (as in some EFL contexts) in which fluent speakers of English are generally not available to provide other kinds of language input.

Nunan (2006) believes that early works in second language reading assumed it as a passive skill. This view holds that the reader reconstructs the intended meaning by recognising the printed letters and words and builds up meaning from the smallest units in the text or at the 'bottom' to larger units at the 'top'.

Based on Kashani Mahmood (2013), a number of studies on ESL/EFL reading show some common obstacles encountered by Iranian EFL learners. According to some teachers teaching English in an EFL context, like Iran, could help students to read an essay better than the other text genres such as newspaper articles, poems, or novels. Based on his investigation, many students lack background knowledge about the target culture. Most of them adopt a 'word by word' reading strategy for interpreting a text. Even though they understand the meaning of discrete words, they are unable to make connections between them. They lack motivation for reading and do not possess efficient problemsolving abilities for reading comprehension. Finally, most of them do not possess a clear and specific objective for English reading.

According to Nunan (2006), our knowledge and expectations about the world will affect our ability to understand new information. In 1970s, background knowledge was assumed to have a great role in second language reading. Orasana (1986) maintains that 'the knowledge a reader brings to a text is a principal determiner of how that text will be comprehended, and what may be learnt and remembered' (P. 32). Anderson et al. (1983) concluded 'a schema influences learning and memory when it is activated before reading and also aids retrieval when accessed after reading' (P. 43). Hammadou (1991) reported that 'readers with more knowledge about the topic showed more logical (correct) inferences based on the text and fewer illogical (incorrect) inferences' (P: 178).

By considering the discussed factors, it seems necessary for Iranian EFL learners to be equipped with effective reading strategies. One of these reading strategies is using the prior knowledge. If students are good at using effective reading strategies, they may become active, strategic, and independent readers who can adjust their strategies to different reading situations, and are also able to evaluate their products and behaviours for full comprehension of texts (Beckman, 2002).

\subsection{Review of the literature}

Voss and colleagues provided evidence that domain-specific knowledge influences understanding (Chiesi, Spilich, \& Voss, 1979; Means \& Voss, 1985; Voss, Vesonder, \& Spilich, 1980). They found that high-knowledge readers recalled more information than low-knowledge readers and concluded that the former employed their knowledge during reading to construct an organised representation of the text. Prior knowledge can also assist the memory. Recall for abstract information typically improves when additional meaningful information is available (Bartlett, 1932; Bower, Karlin \& Dueck, 1975; Bransford \& Johnson, 1972).

The researchers have investigated the role of prior knowledge in a variety of ways. For instance, Kashani Mahmood (2013) investigated the effect of graphic organisation on reading comprehension. He concluded that Graphic organisers give students maps that they can use to pinpoint, collect, organise, and combine information from a multitude of resources. Students can use this knowledge to develop possible solutions for real-life, messy problems. Teachers may activate students' prior knowledge, cultivate students' meta-cognition, and build up their holistic concept of a given topic for long-term memory by modelling graphic organisers strategy.

In another study, Khosrojerdi (2010) investigated the role of background knowledge and IQ and recall of the texts in advanced learners in Iran. She found that there is no relationship between IQ and recall of the texts in advanced learners in Iran. The researcher believes that one probable explanation for this, rather strange, result may be due to the advanced level of the subjects. In other words, advanced learners are capable of using other skills such as reading comprehension strategies for better a better comprehension of the texts and therefore better recalling. When confronting the unfamiliar texts, advanced learners attempt to use skills other than their background knowledge to comprehend and recall the texts. She also found that the subjects' intelligence has no role or effect on the comprehension and recall of the texts. This finding is not in line with the previous ones.

Caillies and DenhieÁre (2002) investigated the relationship that readers, with different levels of prior knowledge, established between the elements of a procedural text. They found that readers with different levels of prior knowledge differ in regard to reading times, recognition performances, and comprehension questions. The more prior knowledge a reader has, the shorter the reading time, and the higher the percentage of accuracy on comprehension questions. They also found that prior knowledge provides the retrieval structures that give readers direct access to the information they need and when they need it. Thus, high-knowledge readers are able to develop a type of hierarchical retrieval structure, which allows them to automatically retrieve distant information in the surface structure of the text.

In another investigation by Najjari (2002), the researcher tried to prove that preparing the ESP (English for Specific Purpose) learners with the appropriate background information helps them to perform better on discipline-based 
achievement tests. He found that teacher's major role in ESP is to recognise the importance of genre-based activities in building related information in such a way that the new material is easily assimilated into the learners' existing field of knowledge. Due to the fact that comprehending a text can be construed as an interactive process between reader's background knowledge and the text, it is the role of the teacher to give adequate language and context to activate learners' background knowledge on the matter.

\subsection{Purpose of study}

The purpose of teaching English in Iran is to enable students to read, comprehend, and translate various texts in different contexts (Hajibabaei, 2011). In addition, Gabb (2000) identifies a number of barriers, in the realm of reading, the most important of which are limited vocabulary and lack of background knowledge (schematic knowledge). Therefore, students with reading difficulty are to expand their vocabulary and schematic knowledge. The researchers in this study are going to find out whether the Iranian EFL learners' reading comprehension would be improved by background knowledge or not. The aim of this study is, thus, to facilitate the reading comprehension of the Iranian EFL learners through activating their schematic knowledge.

\subsection{Significance of the study}

In Iran, at school level, teachers spend most of their class time on reading because of the dominance of Grammar Translation Method (GTM) on school pedagogy. In addition, the use of proper methods of teaching has been overlooked. At university level, students receive a great amount of reading based on their field of study. But most students have problems in reading comprehension due to lack of required schematic knowledge. Therefore, the activation of schematic knowledge prior to the reading process can be a useful method in teaching reading comprehension in language classes. In fact, the significance of this study is to investigate the relationship between the schematic knowledge and reading comprehension. The researchers are going to find out that whether prior knowledge can facilitate reading comprehension or not. In order to come up with a suitable way to justify these claims, the researchers have tried to investigate the effect of schematic knowledge on Iranian EFL learner's reading comprehension to provide a better understanding of the issue with the results in line with similar studies in the context of Iran.

\subsection{Research question and hypothesis}

This study seeks answers to the following question:

1. Does activating background knowledge (schemata that can be related to the topic), have any significant effect on Iranian EFL reading comprehension?

Accordingly, the following null hypothesis is formulated:

$\mathrm{H}_{0}$ : Activating background knowledge, or schemata related to the topic, does not have any significant effect on Iranian EFL reading comprehension.

\section{Methodology}

\subsection{Participants and grouping}

The participants were 68 male (36) and female (42) students learning English at the intermediate level in a private language institute in Rasht, a city in the north of Iran. The students' ages ranged from 18 to 27, with the mean of 22. The samples were selected randomly and were placed in two separate groups, the control group and the experimental one. Only the experimental group received the treatment which was the schemata activation session. The control group, on the other hand, received no specific treatment.

\subsection{Instruments}

For the purpose of this study, the following instruments were used.

English Proficiency test: the researchers administered it to determine the participants' level of proficiency in English. The test comprised of 50 items having Grammar, Vocabulary and Reading Comprehension sections. The test was obtained from www.transparent.com/learn-englisg/proficiency-test.html and was proved to be highly reliable at the level of $(\mathrm{r}=.9)$ measured against KR-21 through SPSS. To make sure that the participants were homogeneous, General English proficiency test was employed and those participants that fell amongst the scores that were one standard deviation above or below the mean were selected for this study. Then, the participants were divided into two groups. A pretest was carried out first.

Reading Comprehension Pretest: It included twenty-six multiple-choice items for three reading passages. The passages were selected from TOEFL practice test books of Rogers (2002), Gear (2002), and Phillips (2004). The passages varied in topics, to avoid any biases and familiarities, and were almost of the same length having the same number of test items. The participants were given forty-five minutes to do the task, with each correct item having one point only.

Reading Comprehension Post test: The post test results were compared with the pretest results to produce insights on the participants' performance before and after the treatment, i.e. Schemata training, to prove its effectiveness in the participants' performance. The participants took the posttest in the time limit of forty-five minutes. The content of the post test was highly similar to that of the pretest, with the same scoring method. Regarding the schemata group, they were asked to read a short passage related to the main reading passage before reading and answer the reading comprehension questions for the posttest. 
Schemata Activation: In a ninety-minute session, the participants in the experimental group were taught to determine the purpose of reading before a given passage. The instructor made them aware of the text structures. Before going to the main text, they were handed a short paragraph to read which was related to the main text in order for their background knowledge to be activated. The participants were also instructed to come up with some questions from the short paragraph they read earlier enabling them to find the answers after the main text was read. All in all, the instructors taught three main schemata activation techniques to the participants. The techniques were generating questions about the text, connecting with the text, and evaluating what they had learnt.

\subsection{Procedure}

The whole process of data collection was carried out in three days. In the first day the Proficiency test was administered. Among 90 students in a private language institute in Rasht 68 students were selected based on an English Proficiency test (19 were left out due to lack of homogeneity with the others and 3 were not present during the pretest or the treatment session). The session was allocated 60 minutes of time. The next day the participants were divided into two groups, one group as the experimental group and the other as the control group. Both groups received a pre-test during a forty-five-minute session. On the third session, the treatment was carried out only on the experimental group in about 90 minutes. Before each reading passage, the teacher tried to activate the learners' background knowledge in the experimental group. The participants answered the following multiple choice questions, and after the pretest the treatment lesson took place. The experimental group received the treatment before reading in the schemata session in order for their background knowledge to be activated. The control group did not receive any specific treatment. Finally, the participants in both groups took the post test, in which they read the reading comprehension passages and answered the questions at the end of the session, and the results were analysed accordingly.

\subsection{Data Analysis}

The researchers used the mean and standard deviation to point out the differences between the performances of the two groups during the pretest. In order to analyse the data quantitatively, after the post test, the t-test method was employed to determine the differences between the two groups. Finally, SPSS (Statistical Package for Social Sciences), which is a computer software, was used to analyse the data in the present study. The statistical level of significance was set at .05.

\section{Results and discussion}

At the beginning a pretest was carried out to show that there were not any preexisting differences between the two groups as displayed by Table 2. The value of the observed t was 0.06 , lower than the value of t-critical 2.012 at 0.05 freedom degrees. This shows that the difference between the means of the control and the experimental group was not significant statistically. Table 1 displays the figures.

Table 1. T-test for the means of pre-test of control and experimental groups

\begin{tabular}{cccc}
\hline & df & $\begin{array}{c}\text { t-test for the } \\
\text { means }\end{array}$ & Sig (2-tailed) \\
\hline Reading Pretest & 66 & $\mathrm{~T}=0.06$ & 2.012 \\
\hline $\mathrm{P}<.05$ & & &
\end{tabular}

As it is obvious from table 2, the mean scores the means of control and experimental groups were 19.64 and 19.43 respectively, which according to table 1 , was not statistically significant.

Table 2. Pre-test Results

\begin{tabular}{cccc}
\hline Groups & Mean & Number & Standard deviation \\
\hline Control & 19.64 & 34 & 3.38 \\
Experimental & 19.43 & 34 & 3.62 \\
\hline
\end{tabular}

Table 3 deals with the post test and demonstrates the differences that are made after getting familiar with the relevant schemata you can see that statistics derived from post-test shows drastic changes in this group which are significant statistically.

Table 3. Posttest Results

\begin{tabular}{ccccc}
\hline Groups & $\begin{array}{c}\text { Standard } \\
\text { deviation }\end{array}$ & Mean & St. mean error & T \\
\hline Control & 3.93 & 19.0 & .665 & -2.39 \\
\hline Experimental & 4.05 & 21.6 & .688 & -2.38 \\
\hline
\end{tabular}


As obvious from the statistics, the post test of experimental group shows higher mean and implies that this group has improved drastically in these tests. Tables 3 and 4, display significant difference in posttest results between the means of the two groups, with the experimental group outperforming the control group.

Table 4. T-test for the means of post-test of control and experimental groups

\begin{tabular}{cccc}
\hline & df & $\begin{array}{c}\text { t-test for the } \\
\text { means }\end{array}$ & Sig (2-tailed) \\
\hline Reading Posttest & 66 & $\mathrm{~T}=0.02$ & 2.012 \\
\hline $\mathrm{P}<.05$ & & &
\end{tabular}

Tables 3 and 4 reject our hypothesis that there is no relationship between schemata knowledge and reading skill. In other words, a significant difference was observed between the means of control and experimental group $(d f=66$ and level of significance $=0.05$ ) which explains the efficiency of the treatment. Those students who were provided with the schematic information outperformed the control group. This shows that prior knowledge plays a crucial role in comprehending a text in both micro and macro level. In summary, in macro level, prior knowledge will help students to understand the whole text better and deduce the whole meaning. In micro level prior knowledge will help them to guess different word meanings, their roles, and their parts of speech in different situations.

\section{Conclusion}

Based on the schema theory, our knowledge is organised as a network of ideas. A great number of learner problems may result from insufficient general knowledge, and cultural awareness. Background knowledge can play a role as it gives them insight into what the text is about with reference to culture and general knowledge. Goodman (1967) defined reading as a psycholinguistic guessing game. If the students employ background knowledge to figure out the meaning of unfamiliar or new words, it could also compensate for the words that they do not know and raises their selfconfidence. When people receive new information their schemata change and the new information becomes related to the old information.

The data found in this study is in line with those of Carrel's study (1987) in which the results indicated that learners' comprehension and recall increased if they had familiarity with passages they read . In another study, Rawson and Kintsch (2004) concluded that providing readers with prior knowledge before reading improves comprehension. In general, if students have sufficient "prior knowledge" on the specific subject, any teaching approach will do for students' learning. On the other hand, if students "prior knowledge" is less than sufficient, more support is needed, and this support should help students to deal with reconstructing the message from the text and storing it in the memory (Rosenshine, 1986).

The findings of this study reveal that background knowledge has an important effect on reading comprehension. If the learners are provided with background knowledge and systemic information their comprehension will enhance accordingly. Schemata theory plays a very important role in reading comprehension. It could be used as an efficient method of teaching English and specifically reading comprehension. It is extremely crucial for teachers to activate learners' background knowledge and raise their attention prior to the reading process. This could be achieved by choosing relevant, familiar, and authentic topics for reading activities in order for the learners to be able to predict what the passage is a bout for a richer understanding of it.

\section{References}

Alfassi, M. (2004). Reading to learn: Effects of combined strategy instruction on high school students. The Journal of Educational Research 97(4), 171-184.

Anderson, R. C. et al (1983). Effects of the Reader's Schema at Different Points in Time. Journal of Educational Psychology, 75, 271-9.

Bartlett, F. C. (1932). Remembering: A study in experimental and social psychology. Cambridge, England: Cambridge University Press.

Beckman, Pat. (2002). Strategy instruction. The ERIC Clearinghouse on Disabilities and Gifted Education (ERICEC).

Biemans, H.J.A., Deel, O.R. \& Simons, P.R. (2001). Differences between successful and less successful students while working with the CONTACT-2 strategy. Learning and Instruction, 11, 265-282.

Bower, G. H., Karlin, M. B. \& Dueck, A. (1975). Comprehension and memory for pictures. Memory and cognition, 3,216-220.

Bransford, J. D., \& Johnson, M. K. (1972). Contextual prerequisites for understanding: Some investigations of comprehension and recall. Journal of Verbal Learning and Verbal Behavior, 11, 717-726. 
Caillies, S., \& DenhieÁre, G., \& Kintsch,W. (2002). The effect of prior knowledge on understanding from text: Evidence from primed recognition. European Journal of Cognitive Psychology, 14 (2), 267-286.

Carrell, P.L. (1987). The effects of rhetorical organization on ESL readers. TESOL Quarterly, 18, 441-469.

Celce- Murcia, M. (2001). Teaching English as a Second or Foreign Language. Heinle \& Heinle Publishers.

Chall, J.S. (1983). Stages of reading development. New York: McGraw-Hill.

Chiesi, H.L., Spilich, G.J., \& Voss, J.F. (1979). Acquisition of domain related information in relation to high and low domain knowledge. Journal of Verbal Learning and Verbal Behavior, 18, 257-273.

Dochy, F., Segers, M. \& Buehl, M.M. (1999). The relation between assessment practices and outcomes of studies: The case of research on prior knowledge. Review of Educational Research, 69(2), 145-186.

Gabb, S. (2000). From talk to print: Preparing students to read with ease. Field Notes, 10 (2).

Goodman, K. S. (1994). Reading, writing and written texts: A transactional socio-psycholinguistic view. In

R. Ruddell, M. Ruddell, \& H. Singer (Ed.).DE: International Reading Association.

Hammadou, J. (1991). Interrelationships Among Prior Knowledge, Inference, and Language Proficiency in Foreign Language Reading. THE MODERN LANGUAGE JOURANL, 75, 27-38.

Kashani Mahmood, M., \& Reymani Nikoo, F., \& Bonyadi, A.(2013). The Role of Schema or Background Knowledge Activation and Graphic Organizer on Increasing Iranian EFL Learners' Reading Comprehension. European Online Journal of Natural and Social Sciences. Vol.2, No.2 Special Issue on Teaching and Learning.

Khosrojerdi, M. (2010). On The Effect of Background Knowledge and IQ on Reading Comprehension and Recall Process of a Group of Iranian Advance Students. Retrieved from: www. profdoc.um.ac.ir/articles/a/1033353.pdf.

Macaro, E., \& Vanderplank, R., \& Graham, S. (2005). A systematic review of the role of prior knowledge in unidirectional listening comprehension. London: EPP Centre, Social Science Research Unit, Institute of Education, University of London.

Means, M.L., \& Voss, J.F.(1985). Star wars: A developmental study of expert and novice knowledge structures. Journal of Memory and Language, 24, 746-757.

Nunan, D. (2006). Second Language Teaching \& Learning. Boston: Heinle \& Heinle Publishers.

Orasana, J. (ED), (1986). Reading comprehension from research to practice. Hillidale: Lawrence Erlbaum Associates Publishers.

Rawson, K.A. \& Kintsch, W. (2004). Exploring encoding and retrieval effects of background information on text memory. Discourse Processes, 38, 323-344.

Squire, J.R. (1983). Composing and comprehending: Two sides of the same basic process. Language Arts, 60, 581589.

Stahl, S. A., Hare, V. C., Sinatra, R., \& Gregory, J. F. (1991). Defining the role of prior knowledge and vocabulary in reading comprehension: The retiring of number 41. Journal of Reading Behavior, 23, 487508.

Schallert, D.L. (1982). The significance of knowledge: A synthesis of research related to schema theory. In W. Otto \& S. White (Eds.), Reading expository prose (pp. 13-48). New York: Academic.

Tarchi, C. (2009). Reading comprehension of informative texts in secondary school: A focus on direct and indirect effects of reader's prior knowledge. Learning and Individual Differences, 20, 415-420.

Voss,J.F., Vesonder, G.T., \& Spilich, G.J. (1980). Text generation and recall by high knowledge e and low-knowledge individuals. Journal of Verbal Learning and Verbal Behavior, 19, 651-667.

Weisberg, R. (1988). 1980s: A change in focus of reading comprehension research: A review of reading/learning disabilities research based on an interactive model of reading. Learning Disability Quarterly, 11, 149-159. 